\title{
SYSTEMATIC REVIEW OF NEOTROPICAL LAUXANIIDAE GENERA TRICONOPSIS HENDEL (DIPTERA, SCHIZOPHORA)
}

\author{
Vera Cristina Silva ${ }^{1}$
}

\begin{abstract}
A review of the Neotropical Lauxaniidae genus Triconopsis Hendel, 1914 is presented with redescription of $T$. longicornis Hendel, 1914 and the description of $T$. caioalbertsi sp.n. (type locality Uruguay), including illustrations and a key.

KEY WORDS. Diptera, Lauxaniidae, Triconopsis, Neotropical region, new species
\end{abstract}

HENDEL (1914) erected the genus Triconopsis with one species T. longicornis Hendel, 1914, from Paraguay. Another reference to this genus was made by HENDEL (1925) in his key for the identification of the Lauxaniidae genera, and since then the genus has not been cited. While identifying material from the AMNH collection, a new species, described below, was found. The collections which had material analysed in this study are listed below, with their respective acronyms, and curators: (AMNH) American Museum of Natural History, New York, Dr. D. Grimaldi; (MZSP) Museu de Zoologia, Universidade de São Paulo, São Paulo, Dr. F.C. do Val; (NHMW) Naturhistorisches Museum, Vienna, Dr. R. Contreras-Lichtenberg; (USNM) National Museum of Natural History, Washington, D.C., Dr. A.L. Norrbom and Dr. G.F. Hevel.

\section{Triconopsis Hendel, 1914}

Triconopsis Hendel, 1914: 153. Type species, Triconopsis longicornis Hendel (orig. des.).

Diagnosis. Face with three humps; frons wider than long; antenna with scape longer than pedicel, first flagellomere very long, rod-like; arista white, plumose; ocellar setae long; anterior orbital seta converging; dorsocentral setae $0+2$; acrostichal seta absent; 1 katepisternal seta; wing spotted or clouded.

\section{Triconopsis longicornis Hendel, 1914}

\section{Figs 1-7}

Triconopsis longicornis Hendel, 1914: 154. Type locality: Paraguay, San Bernardino.

Distribution. Southern Brazil, Argentina, Paraguay.

Redescription. Head (Figs 2, 3): vertex carenate; ocellar triangle well developed, close to the vertex, black. Frons rectangular, wider than long, dark brown,

1) Departamento de Ciências Biológicas, Faculdade de Ciências e Letras de Assis, Universidade Estadual Paulista. Avenida Dom Antonio 2100, 19800-000 Assis, São Paulo, Brazil.

E-mail: bsvera@femanet.com.br 
with pollinosity; with velvet black parts: a stripe in the orbital margin extending to the parafacialia and a small stripe between posterior dorsocentral seta and ocellar seta; anterior margin pointed, yellowish. Face wide, smooth and shining, yellowish brown; with three pointing humps, two in the oral margin and the third above both, with blackish apices. Eye oval. Parafacialia narrow, velvet black, with whitish pruinosity. Gena wide, dull black, anterior part white pruinose. Occiput dull black. Antenna with scape slightly longer than the pedicel, light brown; both with long apical ventral setae; pedicel with dorso-basal setae and many small ones in the ventro-posterior side; first flagellomere black, at least six times so long as its basal width. Arista longer than the first flagellomere, white, plumose, with long dorsobasals hairs. Chaetotaxy: outer vertical $2 / 3$ inner vertical setae; ocellar seta long, diverging; anterior orbital setae forwards, converging in the apex, smaller than posterior orbital; posterior orbital setae reclinated; postocellar setae converging, small; 2 genal small setae. Mouth parts brown; palpi black, long and slender.

Thorax. Mesonotum, pleurae and scutellum dull black, with white pruinosity. Scutellum approximately triangular. Chaetotaxy: dorsocentral setae $0+2 ; 1$ postpronotal seta; 2 notopleural setae; 1 intralar seta; $1+1$ supralar setae; 1 postalar seta short; acrostichal seta absent, only two rows of hairs; anepimerumon bare; 1 katepisternal seta; 1 anepisternal seta; 1 short proepisternal seta; 2 strong scutellar setae.

Wing (Fig. 1). Brown, with hyaline spots in the apex, at the base and in four other places in the membrane; costals bristles not extending until the apex of $\mathrm{R}_{4+5}$; base of Rs bare; crossvein r-m after the middle of discal cell; crossvein dm-cu in the basal third of cell $\mathrm{r}_{4+5}$; longitudinal veins approximately in parallel. Halteres whitish yellow.

Legs. Fore legs darker, hind one yellowish. Second and third fore tarsomeres stouter than the others. Fore coxa, second to fifth fore tarsomeres, all median and hind tarsomeres, middle and hind (except base) tibiae, white; fore femur and tibiae, first fore tarsomere, black; all other segments, including base of hind tibia, brown, except two basal thirds of hind femur brownish yellow. Chaetotaxy: fore coxa with dorsal pre-apical and apical bristles; fore femur with posterior median row of setae and two pre-apical postero-ventral setae; all tibiae with one pre-apical dorsal seta; middle tibia with strong apical ventral setae; hind femur with pre-apical dorso-anterior seta; hind tibiae with apical ventral seta.

Abdomen: narrow, dull black; longer setae in the margins of tergites. Male terminalia (Figs 4, 7): epandrium without surstilar expansion; gonostyli small; cerci small; hypandrium narrow; aedeagus membranous, boat-shaped (open ventrally), with two rows of short teeth and one extremely long setiform process with bifid apex in the median internal part; aedeagal apodema well developed. Female terminalia (Fig. 5): short and blunt. Segments 7 and 8 without modifications. Epiproct very small; hypoproct small, with rounded apex. Cercus small, papillate. Genital chamber very long, thin membranous, ending below the sternite 8 . Three sclerotized rounded spermathecae, arranged $1+2$; with reforced enlarged base of the spermathecal ducts; the paired spermathecae with very short own duct: ducts fused into one shortly behind the sclerotized distal part (Fig. 6). 


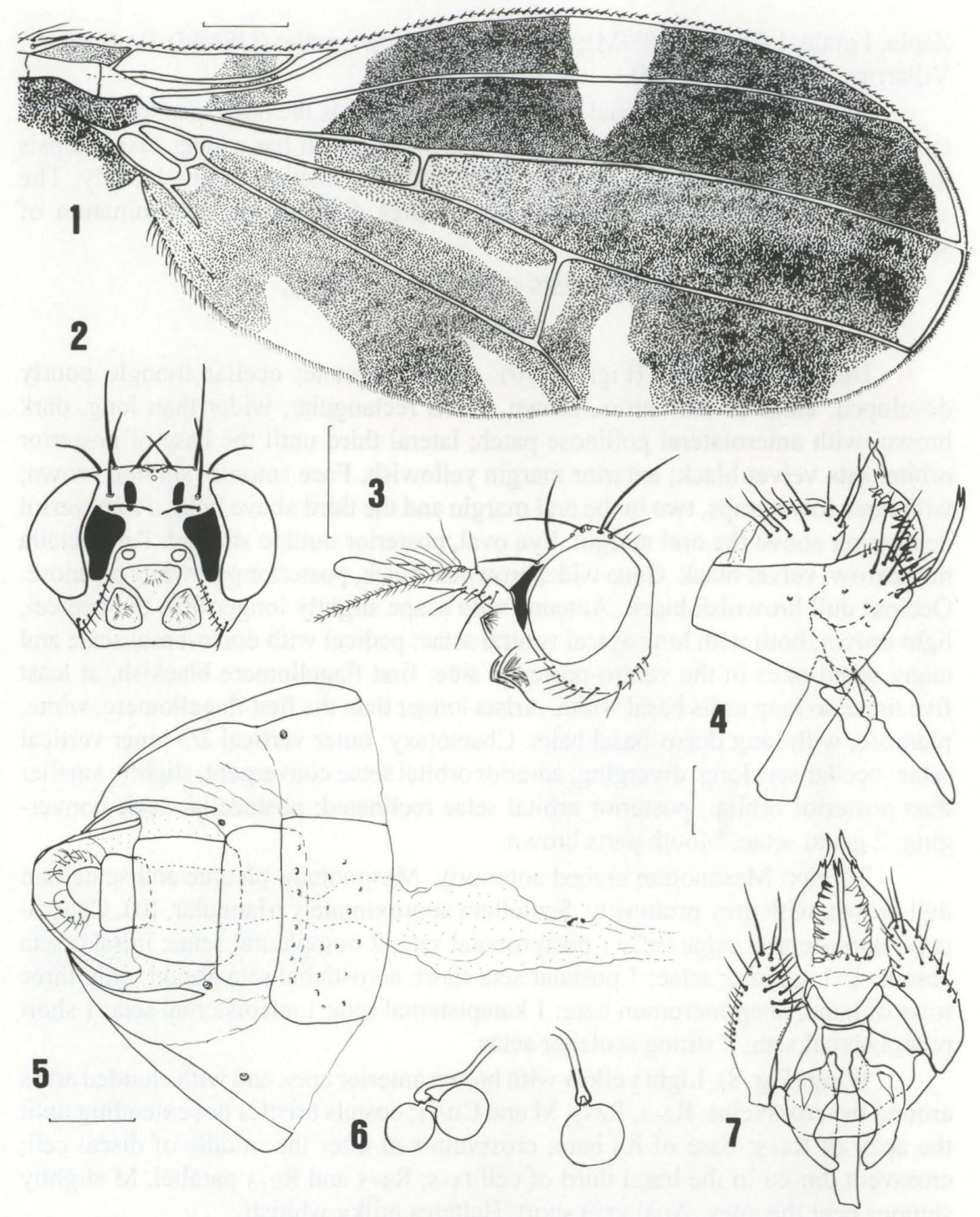

Figs 1-7. Triconopsis longicornis, Paraguay, San Bernardino, holotype. (1) Right wing; (2) head, frontal view; (3) head, lateral view. Brazil, Itaporanga, male terminalia: (4) left lateral view; Brazil, Barueri, female terminalia: (5) end of abdomen, ventral view and (6) spermathecae; (7) Brazil, Itaporanga, male terminalia, posteroventral view. Scales $0,1 \mathrm{~mm}$, except figures 2 and $3,0,5 \mathrm{~mm}$ and 4 and $7,0,05 \mathrm{~mm}$.

Material examined. Holotype male: Paraguay: San Bernardino, Fiebrig leg. (NHMW). BRAZIL, Rio de Janeiro: Rio de Janeiro, 1 ? (MZSP); São Paulo: Itaporanga, 1 male, 1 female (MZSP); Cajuru, Cássia dos Coqueiros 1 male (MZSP); Barueri, 1 male, 3 females (MZSP); Cotia, 1 male (MZSP). ARgENTINA, Jujuy: 
Zapla, 1 male, 1 female (USNM); Guemas de Salta, 2 females (USNM). PARAGUAY: Villarrica, 2 males (USNM).

Comments. The material indicated as holotype is the only specimen attributable to Triconopsis longicornis Hendel in the NHMW. It has a label "Triconopsis longicornis H., det Hendel", plus the label with information on the locality. The specimen is covered with fungous, what makes difficult the determination of specimen gender.

\section{Triconopsis caioalbertsi sp.n.}

Figs 8-12

Description. Head (Figs 9, 10): vertex carenate; ocellar triangle poorly developed, close to the vertex, brown. Frons rectangular, wider than long, dark brown, with anterolateral pollinose patch; lateral third until the base of posterior orbital seta velvet black; anterior margin yellowish. Face smooth, shining brown; with three low humps, two in the oral margin and the third above both; a transversal depression above the oral margin. Eye oval, posterior outline straight. Parafacialia not narrow, velvet black. Gena wide, brownish black, posterior part white pruinose. Occiput dull brownish black. Antenna with scape slightly longer than the pedicel, light brown; both with long apical ventral setae; pedicel with dorso-basal setae and many small ones in the ventro-posterior side; first flagellomere blackish, at least five times so long as its basal width. Arista longer than the first flagellomere, white, plumose, with long dorso-basal hairs. Chaetotaxy: outer vertical $2 / 3$ inner vertical setae; ocellar seta long, diverging; anterior orbital setae convergent, slightly smaller than posterior orbital; posterior orbital setae reclinated; postocellar setae converging; 2 genal setae. Mouth parts brown.

Thorax: Mesonotum arched anteriorly. Mesonotum, pleurae and scutellum dull brown, with grey pruinosity. Scutellum approximately triangular, flat. Chaetotaxy: dorsocentral setae $0+2 ; 1$ postpronotal seta; 2 notopleural setae; intralar seta absent; $1+1$ supralar setae; 1 postalar seta short; acrostichal seta absent, only three rows of hairs; anepimerumon bare; 1 katepisternal seta; 1 anepisternal seta; 1 short proepisternal seta; 2 strong scutellar setae.

Wing (Fig. 8). Light yellow with brown anterior apex and with clouded areas around the crossveins, $\mathrm{R}_{2+3}, \mathrm{R}_{4+5}, \mathrm{M}$ and $\mathrm{CuA}_{1}$; costals bristles not extending until the apex of $\mathrm{R}_{4+5}$; base of Rs bare; crossvein $\mathrm{r}-\mathrm{m}$ after the middle of discal cell; crossvein dm-cu in the basal third of cell $\mathrm{r}_{4+5} ; \mathrm{R}_{4+5}$ and $\mathrm{R}_{2+3}$ parallel, $\mathrm{M}$ slightly sinuous near the apex. Anal vein short. Halteres milky whitish.

Legs. Yellow, but fore tibia and first fore tarsomere brownish; second to fifith fore tarsomeres white. Chaetotaxy: fore coxa with dorsal pre-apical and apical bristles; fore femur with posterior and ventral rows of setae; all tibiae with one pre-apical dorsal seta; middle tibia with strong apical ventral setae.

Abdomen. Narrow, shining blackish brown, with yellowish polinosity; longer setae in the margins of tergites. Male terminalia (Figs 11, 12) with epandrium without surstilar expansion; gonostyli well developed, digitiform; aedeagus membranous, wide triangular, with two rows of small stilets and a pointed structure in the median internal part; aedeagal apodema developed. Hypandrium small, narrow. 

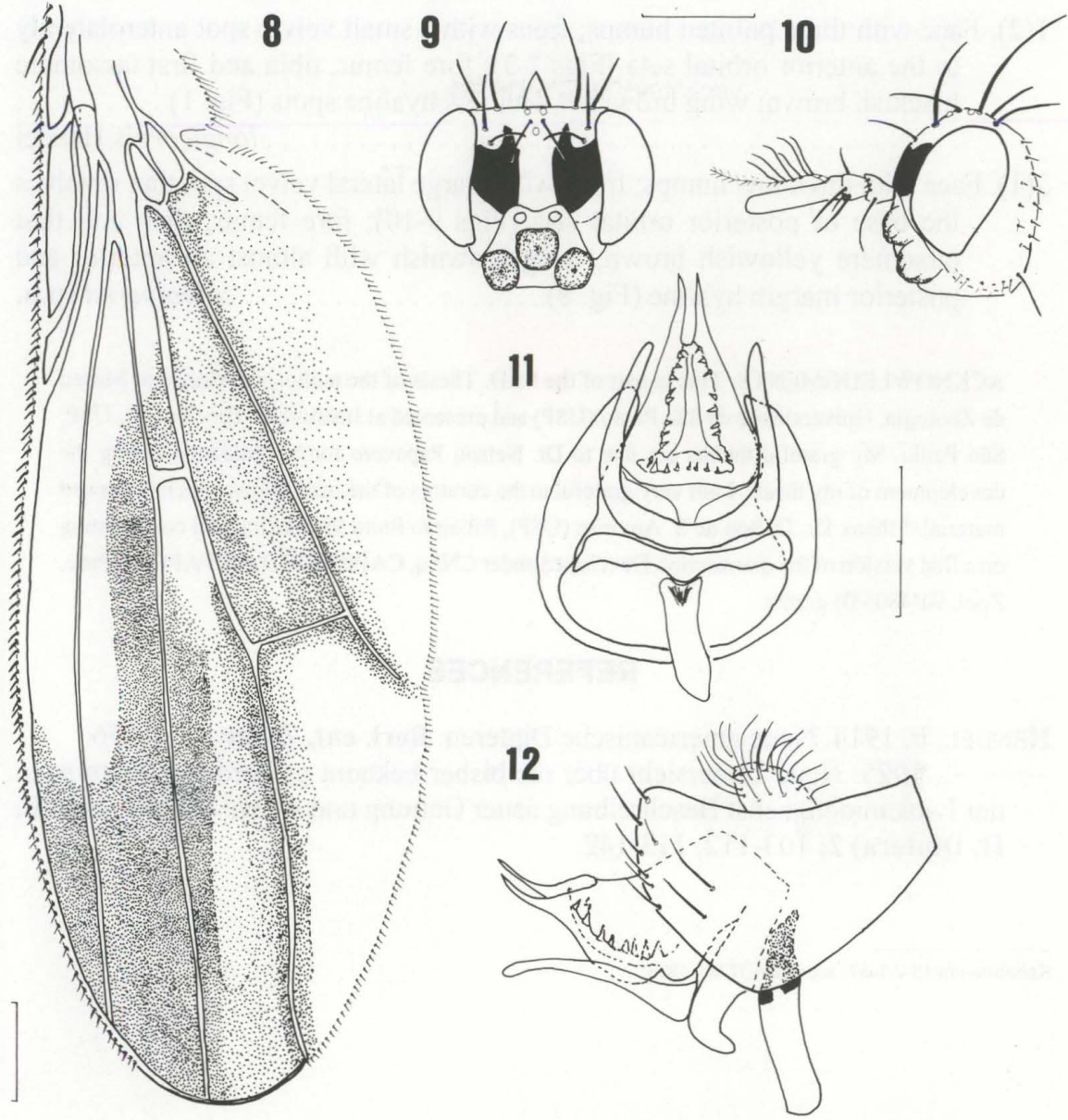

Figs 8-12. Triconopsis caioalbertsi sp.n., Uruguay, holotype. (8) left wing; (9) head, frontal view; (10) head, lateral view; (11) male terminalia, posteroventral view and (12) right lateral view. Scales $0,1 \mathrm{~mm}$, except figures 9 and $10,0,5 \mathrm{~mm}$.

Female unknown.

Material examined. Holotype male: URuguay, Dept. of Rio Negro: $15 \mathrm{Km}$ s. Paysandu, 27.XII.1962 - 06.I.1963, R. G. Van Gelder leg. (AMNH).

I dedicate this new species to the first-born of Dr. Carlos Camargo Alberts, a good friend and a colleague in Zoology who have always helped me with suggestions and encouragement. 


\section{Key with characters to distinguish the two species of Triconopis}

1(2). Face with three pointed humps; frons with a small velvet spot anterolateraly to the anterior orbital seta (Figs 2-3); fore femur, tibia and first tarsomere blackish brown; wing brownish with few hyaline spots (Fig. 1) ........ longicornis Hendel

2(1). Face with three low humps; frons with a large lateral velvet spot that involves the base of posterior orbital seta (Figs 9-10); fore femur, tibia and first tarsomere yellowish brown; wing brownish with almost all anterior and posterior margin hyaline (Fig. 8) ............... caioalbertsi sp.n.

ACKNOWLEDGMENTS. This is part of the Ph.D. Thesis of the author, developed at Museu de Zoologia, Universidade de São Paulo (USP) and presented at Instituto de Biociências, USP, São Paulo. My grateful thanks are due to Dr. Nelson Papavero for his guidance during the development of my thesis. I am very grateful to the curators of the institutions which borrowed material. I thank Dr. Dalton de S. Amorim (USP), Ribeirão Preto for reading and commenting on a first version of the manuscript. Developed under CNPq, CAPES/PICD and FAPESP (Proc. Zool. 94/4805/0) grants.

\section{REFERENCES}

HENDEL, F. 1914. Neue americanische Dipteren. Berl. ent. Ztchr.: 151-176. 1925. Neue Uebersicht über die bisher bekannt gewordenen Gattungen der Lauxaniden, nebst Beschreibung neuer Gattung und Arten. Encycl. ent. (B, II, Diptera) 2: 103-112, 113-142.

Recebido em 15.V.1997; aceito em 17.VIII. 1998. 